\title{
Analysis of the correlation between ophthalmic examination and quality of life outcomes following intracorneal ring segment implantation for keratoconus
}

\author{
Avaliação dos fatores que influenciam na qualidade de vida de pacientes com ceratocone após \\ implante de anel intraestromal
}

Juliane de Freitas Santos Paranhos ${ }^{1}$, Augusto Paranhos Jr. ${ }^{2}$, Marcos Pereira Ávila $^{3}$, Paulo Schor ${ }^{2}$

\begin{abstract}
Purpose: To analyze the correlation between quantitative measurements outcomes and keratoconus patients' vision related quality of life ( $\mathrm{v}-\mathrm{Q} \mathrm{QL})$ following intrastromal corneal ring segment implantation.

Methods: The NEI-RQL (National Eye Institute Refractive Error Quality of Life) was administered to patients requiring intrastromal corneal ring segment implantation, before and after surgery, wearing best correction for 40 days minimum. Visual acuity, refraction, corneal topography, aberrometry data (VOL-CT. software) and contrast sensitivity were recorded before and 3 months after surgery. The main outcome measures were best corrected visual acuity, refraction, steep keratometric value (Kmax), aberrometry, contrast sensitivity and v-QoL.

Results: There were 42 keratoconic patients ( 69 eyes): 19 male and 23 female, mean age $24.9 \pm 5$ years in this prospective study. Binocular best corrected visual acuity improved $(0.13 \pm 0.03$ before to $-0.01 \pm 0.01 \log M A R$ after surgery, $\mathrm{p}<0.001)$. There was a statistically significant improvement in mean spherical refraction (2.81 \pm 0.44 to $1.71 \pm 0.31$ ), cylinder component $(3.89 \pm 0.22$ to $1.82 \pm 0.21)$, spherical equivalent $(4.55 \pm 0.46$ to $2.40 \pm 0.30), K \max (55.92 \mathrm{D} \pm 0.62$ to $52.16 \mathrm{D} \pm 0.58 \mathrm{D})$ and root mean square low order $(\mathrm{p}<0.001)$. Contrast sensitivity (CS) improved at all spatial frequencies: at 6 cpd improvement was higher. Root mean square higher order did not improved $p=0.422$. There was significant improvement across all NEI-RQL scales after surgery. Multivariate analysis showed that gender (males more satisfied than females), cylinder (1 D reduction improves 5 points in general NEI-RQL scores) and normal contrast sensitivity at 3 and $6 \mathrm{cpd}$ were correlated with $v$-QoL. Other variables such as best corrected visual acuity, root mean square low order, root mean square higher order and Kmax did not show influence on NEI-RQL scores.

Conclusions: The best patient response predictors with the NEI-RQL instrument were gender, normal CS at 3 and 6 cpd and cylinder reduction. The use of this questionnaire was crucial to assess the influence of optical tests on $\mathrm{v}$-QoL in keratoconus patients who were referred for intrastromal corneal ring segment implantation.
\end{abstract}

Keywords: Cornea; Corneal topography; Corneal stroma/surgery; Keratoconus; Keratoplasty, penetrating; Quality of life; Patient satisfaction; Visual acuity; Aberrometry

\section{RESUMO}

Objetivo: Analisar a correlação entrefatores relacionados aos pacientes com ceratocone esuas medidas quantitativas e os resultados da qualidade devida com o implante do anel intraestromal (ICRS).

Métodos: O questionário de qualidade de vida relacionado a visão (QdV-V) NEl-RQL (National Eye Institute Refractive Error Quality of Life) validado na língua portuguesa fo: administrado a pacientes com indicação de implante do anel intraestromal antes e depois da cirurgia quando eles já estavam usando a correção por pelo menos 40 dias. Acuidade visual com a melhor correção, topografia de córnea, aberrometria e sensibilidade ao contraste foram medidos antes e três meses após a cirurgia.

Resultados: Foram incluidos neste estudo prospectivo 42 pacientes (69 olhos): 19 homens e 23 mulheres com idade média de 24,9 \pm 5 anos. Houve melhora estatisticamente significante na acuidade visual com a melhor correção binocular $(0,13 \pm 0,03$ antes para $-0,01 \pm 0,01$ logMAR após a cirurgia, $p<0,001)$, na refração esférica média $(2,81 \pm 0,44$ para 1,71 $\pm 0,31)$, no componente cilíndrico $(3,89 \pm 0,22$ para 1,82 $\pm 0,21)$, no equivalente esférico $(4,55 \pm 0,46$ para 2,40 $\pm 0,30)$, na ceratometria máxima $(55,92 \mathrm{D} \pm 0,62$ para $52,16 D \pm 0,58 D)$ e no RMS (root mean square) de baixa ordem $(p<0,001)$. O RMS de alta ordem não teve melhora significante $p=0,422$. A sensibilidade ao contraste (SC) melhorou significativamente em todas as frequências especialmente na de $6 \mathrm{cpg}$. Houve melhora significanteem todas as escalas do NEI-RQL após a cirurgia. A análise multivariada mostrou que sexo (homens com melhores indices de $Q d V-v$ que as mulheres), cilindro (1 D de redução aumenta em 5 pontos a escala geral do NEI-RQL) e SC normal nas frequências de 3 e 6 cpg são os fatores que interferem nos escores de $Q d V$-v dos pacientes com implante de anel intraestromal. As outras variáveis como acuidade visual com a melhor correção, aberrometria e ceratometria máxima não influenciaram nos escores do NEI-RQL.

Conclusões: Os fatores que se correlacionam a melhores pontuações na QdV-V dos pacientes com implante de anel intraestromal são: sexo, SC normal nas frequências de 3 e 6 cpg e diminuição do cilindro. A análise das medidas objetivas em conjunto com o NEl$R Q L$ foifundamental para identificar os fatores que influenciam nos resultados subjetivos dos pacientes com ceratocone e implante de anel intraestromal.

Descritores: Córnea; Topografia da córnea; Substância própria/cirurgia; Ceratocone; Ceratoplastia penetrante; Qualidade de vida; Satisfação do paciente; Acuidade visual Aberrometria

\section{INTRODUCTION}

Keratoconus is a progressive non-inflammatory ectatic disorder that affects young individuals and results in vision impairment ${ }^{(1)}$. Central corneal scarring and increased corneal aberrations are associated with decreased visual acuity ${ }^{(2,3)}$. It affects both eyes in most cases, and is usually associated with eye-rubbing ${ }^{(1)}$.
A keratoconus patient's vision is usually corrected by spectacles, followed by contact lenses. Surgical procedures are indicated when patients are contact lens-intolerant or when spectacles and contact lenses fail to provide an acceptable visual function. A wide variety of surgical procedures are in practice to treat keratoconus. Corneal graft may be complicated by graft rejection, irre-
Submitted for publication: June 20, 2011

Accepted for publication: November 9,2011

Study carried out at the Federal University of Goiás - CEROF.

Physician, Cornea, Post graduation, Universidade Federal de São Paulo - UNIFESP - São Paulo (SP), Brazil. Professional performance in Goiânia (GO), Brazil.

Physician, Departamento de Oftalmologia, Universidade Federal de São Paulo - UNIFESP - São Paulo (SP), Brazil.

${ }^{3}$ Professor, Departamento de Cirurgia, Universidade Federal de Goiás - UFGO - Goiânia (GO), Brazil.
Funding: No specific financial support was available for this study.

Disclosure of potential conflicts of interest: J.F.S.Paranhos, None; A.Paranhos.Jr., Consultant (Allergan, Opto), Financial Support (Fapesp, CNPq), Recipient (Allergan, Alcon, MSD, FAPESP, FADA-UNIFESP), Board Member (Allergan, MSD); M.P.Ávila, None; P.Schor, Consultant (LaserFocus, Alcon), Financial Support (FAPESP), Patent - no money involved (UNIFESP), Board Member (IPEPO).

Correspondence address: Juliane F. S. Paranhos. Hospital da Visão. Rua 38, 300 - Setor Marista Goiania (GO) - 74150-250 - Brazil - Email: ju.fsp@hotmail.com

Ethical Comitee: UNIFESP 0490/06 e UFG 027/06 
gular astigmatism, corneal opacification and glaucoma resulting in visual impairment ${ }^{(1,4-6)}$.

Intrastromal corneal ring segment (ICRS) implantation is a less invasive surgical option with acceptable clinical results reported ${ }^{(7-11)}$. It is an additive procedure: vision rehabilitation is faster than with penetrating keratoplasty (PKP) or deep anterior lamellar keratoplasty (DALK), and without the risk of graft rejection. Recent advances, such as ring implantation aided by femtosecond laser channel dissection, have enhanced the efficacy of intracorneal ring implantation ${ }^{(11,12)}$.

Vision rehabilitation in keratoconus patients is not totally explained by clinical measurements, probably due to the long-term adaptation to optical blur ${ }^{(13,14)}$. Subjective approaches may help to explain the clinical measurements and final result (sense of vision) in these patients ${ }^{(6,13)}$. A previous study showed that ICRS implantation improves keratoconus patients' vision-related QoL (v-QoL) ${ }^{(15)}$.

The objective of this study is to analyze the impact of age, gender, educational level and clinical measures such as visual acuity, contrast sensitivity, aberrometry, keratometric values and refraction on keratoconus patients' v-QoL following ICRS implantation, using the National Eye Institute Refractive Error Quality of Life (NEI-RQL) instrument. We further identify which of these objective measurements are relevant to the keratoconus patient's v-QoL improvement.

\section{METHODS}

This is a prospective study that evaluates keratoconus patients before and after ICRS implantation.

The ethical committees of the Federal University of Goiás and the Federal University of São Paulo approved this study. All patients gave their informed consent prior to the study. All research adhered to the tenets of the Declaration of Helsinki.

Keratoconus patients self-administered a Portuguese validated version of the NEI-RQL instrument prior to the clinical evaluation, in order to avoid any influence of the exams performed during the medical appointment on the patients' answers ${ }^{(13)}$. Patients answered the survey before and after ICRS implantation (Keraring, Mediphacos, Belo Horizonte, Brazil), when they were using their best correction for at least 40 days. The survey consisted of 42 items used to build 13 scales (clarity of vision, expectations, near vision, far vision, fluctuation, activity limitations, glare, ocular symptoms, dependence on correction, suboptimal correction, worry, appearance, satisfaction with correction). The scales were transformed linearly to a 0-to-100 possible range. Lower scores corresponded with lower or poorer quality of life on each subscale. The NEI-RQL was scored according to the guidelines set forth by its authors ${ }^{(15)}$. The participants answered the questionnaire before any vision tests were conducted.

F.A.C.T. (Functional Acuity Contrast Test; Stereo Optical Company, Inc, Chicago, IL) was used to perform a contrast sensitivity (CS) test. It was set at 10 feet and the chart was illuminated between 85 and $100 \mathrm{~cd} / \mathrm{m}^{2}$. The test was performed with spectacle correction. Five spatial frequencies, 1.5 cycles per degree (cpd), $3.0 \mathrm{cpd}, 6.0 \mathrm{cpd}$, $12.0 \mathrm{cpd}$ and $18.0 \mathrm{cpd}$, were measured preoperatively and at 3 months postoperatively. In the analysis of the impact of CS on QoL, the quantitative CS values were dichotomized as 'normal' and 'abnormal'. Values higher than the lower normal limit were considered normal, and abnormal if they were lower. The F.A.C.T. instruction manual provided the inferior normal value.

Best corrected visual acuity (BCVA) with the current correction (spectacles, contact lenses or no correction) of the operated eyes and binocular BCVA were measured using a logMAR chart before and after surgery when patients were using the correction prescribed for at least 40 days. Manifest refraction, slit lamp biomicroscopy, indirect ophthalmoscopy, corneal topography (Medmont) and pachymetry (Sonogage) were performed preoperatively and at 3 months postoperatively. Rigid contact lenses were fitted after surgery if the patients were dissatisfied with visual acuity outcomes during the refraction test. Corneal topography was used to obtain the steep keratometric value (Kmax) and VOL-CT. (Sarver and Associates, Inc, Carbondale, IL) software was used to analyze corneal topographic data in order to obtain the root mean square (RMS) low order (LO) and RMS high order $(\mathrm{HO})$.

\section{Patient selection}

Ophthalmologists of Goiânia were asked to refer us patients with keratoconus that had an indication for ICRS implantation. Indication for ICRS implantation was defined as follows: poor visual acuity with spectacles, intolerance to contact lenses, steep keratometric reading lower than 70 diopters (D) and clear central cornea. Patients that had never tried contact lenses were tested and if the lenses fitted well, the patients were referred back to their physician.

\section{INCLUSION AND EXCLUSION CRITERIA}

Patients with keratoconus that had indication to intracorneal ring segment implantation aged between 18 and 39 years old were included. Patients were excluded if they had other ocular diseases besides keratoconus, systemic conditions that could cause refraction instability (pregnancy, diabetes) or were illiterate and those who refused to comply with the clinical trial schedule and conditions.

\section{SURGICAL TECHNIQUE AND POSTOPERATIVE CARE}

A single surgeon performed all the surgeries between June and October 2007. The manufacturer's nomogram was used to calculate the ICRS (Mediphacos) implant size and location. Kerarings with a $160^{\circ}$ arc size and thickness varying from 150 to $350 \mu \mathrm{m}$ were implanted in all patients. Moxifloxacin $\mathrm{HCl}$ ophthalmic solution $0.5 \%$ (Alcon Inc., USA) was instilled four times 1 hour before surgery and pilocarpine hydrochloride $10 \mathrm{mg} / \mathrm{ml}$ (Allergan Inc., CA) once before surgery.

The surgery was performed under topical anesthesia (proxymetacaine chlorhydrate $0.5 \%$, Alcon Inc., USA). Polyvinylpyrrolidone-iodine (Ophthalmos Inc, Brazil) was used over the conjunctiva and cornea 5 minutes prior to surgery. A circular marker centered on the reflex of the microscope light on the cornea was used to create two concentric circles of 5 and $7 \mathrm{~mm}$. A radial incision set at $80 \%$ of the local corneal pachymetry at the steepest corneal axis was made. This was followed by the creation of one or two concentric stromal tunnels with a curved spatula, consisting of an internal radius of $2.5 \mathrm{~mm}$ and an attempted extension of $170^{\circ}$, inside which the ring segments were implanted.

Post-surgery, patients were instructed to use topical antibiotics t.i.d. for 7 days (moxifloxacin $\mathrm{HCl}$ ophthalmic solution $0.5 \%$ ) and corticosteroids four times a day for 10 days (prednisolone acetate 1\%, Falcon Pharmaceuticals, USA).

\section{Statistical analysis}

Quantitative variables are described by means and standard deviations (SD) if normally distributed by medians and interquartile (IIQ). Paired t and Wilcoxon tests were used to compare binocular BCVA and NEI-RQL scales before and after surgery. For measurements taken per eye, Generalized Estimation Equations (GEE) models were applied in order to take the correction within subject into account. Univariate and multivariate GEE models were also used to analyze the influence of variables on the NEI-RQL general scale. Results from GEE models were expressed by estimated regression coefficients and its standard errors in the analysis of impact factors on QoL. The significance level was set at 0.05. All analyses were performed in the statistical package SAS, version 9.01. 


\section{RESULTS}

Forty-two patients were included in this study. Nineteen (45.2\%) were male and 23 (54.8\%) female. The average age was $24.9 \pm 5$ years (range 18 to 39 years). Most patients (66.7\%) were at or had completed high school, 7.1\% had received basic education and $26.2 \%$ were at or had completed university.

Before surgery 9.5\% wore rigid gas-permeable (RGP) contact lenses, and the other patients were equally distributed between those that used spectacles and those that did not use any optical correction. These patients did not use correction due to poor vision or because they were not able to use RGP contact lenses.

Forty-five patients were included in this study, of which three were excluded: two for ring extrusion in one eye and one that became pregnant during the study. Data were analyzed from the remaining 42 patients. Twenty-seven out of a total of 42 patients had surgery in both eyes while 15 were operated in just one eye, presenting a total of 69 eyes with ICRS implantation. Twelve patients did not have ICRS implants in their other eye due to acceptable vision. The other eye of three patients failed to meet the ICRS implantation criteria - these eyes had significant visual acuity impairment.

The steep keratometric (Kmax) value decreased from $55.92 \mathrm{D}$ to $52.16 \mathrm{D}(0.58)(p<0.001)$

Binocular BCVA with the current correction improved after the surgery $(0.13 \pm 0.03 \log M A R$ before versus $-0.01 \pm 0.01 \log M A R$ after, $\mathrm{p}<0.001)$. The mean BCVA in operated eyes improved significantly from $0.497 \pm 0.026$ preoperatively to $0.297 \pm 0.029$ postoperatively $(p<0.001)$. The mean spherical component of the refraction improved from $2.81 \pm 0.44$ to $1.71 \pm 0.31$, cylinder component improved from $3.89 \pm 0.22$ to $1.82 \pm 0.21$ and spherical equivalent improved from $4.55 \pm 0.46$ to $2.40 \pm 0.30$ ( $p<0.001)$.

Before surgery, 19 patients could not use any correction, 19 wore spectacles and four used RGP lens. After surgery 6 did not need to use any correction, 21 wore spectacles, 4 wore soft contact lenses and 11 used RGP lens.

RMS LO optical aberrations had a statistically significant reduction (mean $3.37 \pm 0.17$ to $2.08 \pm 0.12 \mathrm{p}<0.001$ ), but RMS HO did not $(1.65 \pm 0.14$ to $1.54 \pm 0.10 p=0.4221)$.

Visual function measured by CS improved at all spatial frequencies, though at $6 \mathrm{cpd}$ the improvement was higher $(p<0.001)$.

\section{Questionnaire}

In the univariate analysis, $v$-QoL was influenced by gender (males more satisfied than females), Kmax, spherical equivalent (SE), cylinder, RMS LO and contrast sensitivity at frequencies of 1.5, 3, 6 and $12 \mathrm{cpd}$. However, in the multivariate model only gender, cylinder and CS at frequencies of 3 and 6 cpd remained significant.

There was no relation between QoL improvement and age, educational level, visual acuity, RMS HO and pupil diameter (Table 1).

The general scale improved on an average 5 points when there was 1.0D cylinder reduction, and women scored in mean 8.8 points less than men on the general scale. Abnormality on CS at frequencies of 3 and $6 \mathrm{cpd}$ were related to an impairment of 8.5 and 12.6 scores on the general QoL scale, respectively.

\section{DISCUSSION}

Studies on ICRS implantation have been limited to the use of visual acuity, Kmax and refraction to evaluate its outcomes but many studies shows that visual acuity is not a good parameter to evaluate visual function, especially in keratoconic patients ${ }^{(13-15)}$. In the present study we used the NEI-RQL instrument to assess patients' self-perception to visual changes induced by ICRS implantation and to evaluate the impact of each quantitative measurement on these patients' $v$-QoL. Our results showed that gender (on average, males scored 8.8 points more than females), normal CS at frequencies of 3 and $6 \mathrm{cpd}$ and cylinder reduction (1D reduction on cylinder was related to an increase of 5 points) were the best predictors of keratoconus patients' responses on the NEI-RQL v-QoL instrument. These findings correlate with a study conducted by Fink et al. ${ }^{(16)}$ to characterize gender differences in the CLEK study. Women were more likely than men to undertake repeat visits to their eye care practitioner and report ocular symptoms of dryness and complaints based upon a composite score of ocular symptoms. NEI-VFQ results revealed that sex differences exist in patients' history, vision, and ocular symptoms in keratoconus patients ${ }^{(16)}$.

CS is an important subjective measure of quality of vision. It has been established that daily functional vision improves with a peak CS improvement that is at 3 and $6 \mathrm{cpd}$ approximately ${ }^{(17)}$. This explains why the improvement at these frequencies was related to a better $\mathrm{v}$-QoL after Keraring implantation in this study. Other studies also concluded that the CS was directly related to visual function in keratoconic patients ${ }^{(18)}$.

In the multivariate analysis, QoL was not associated with visual acuity, educational level, age, pupil diameter, RMS LO, RMS HO, Kmax and SE. Although Kmax, SE and RMS LO had significant importance in the univariate analysis, they probably lost importance in the multivariate analysis due to the relationship to the cylinder component of refraction ( $r=0.664$ to Kmax, $r=-0.506$ to RMS LO and $r=0.493$ to SE).

Our study did not find any correlation between age and v-QoL, possibly owing to the fact that patients were in a similar age group and hence it was not possible to correlate this data to patient satisfaction. Pupil diameter and RMS HO were also not related to $\mathrm{V}$-QoL results. The lack of pupil diameter dependence is probably due to the low variation on this metric.

Studies found that higher order aberrations have a negative impact on visual performance in keratoconus and its correction can improve vision ${ }^{(3,19,20)}$. In our study, higher order aberrations were not individually studied but grouped into RMS $\mathrm{HO}$, and this metric may have cancelled some higher order aberrations' impact on vision. Individual Zernike aberrations have different impacts on visual performance and the effect is not necessarily represented by the RMS HO ${ }^{(21,22)}$. This can explain why there was no correlation between $\mathrm{v}$-QoL and RMS HO.

Visual acuity was not related to the patient's satisfaction levels and this confirms earlier findings that high contrast visual acuity may not be the best assessment of visual function ${ }^{(6,18,21,23,24)}$. The brain can perceive and read a 20/20 Snellen high contrast optotype even if the visual acuity chart has a great distortion. ${ }^{(22)}$ The performance of visual function is related to the variation in the individual's neural transfer function and how well their retinal image is processed by neurobiological circuits and interpreted by the neural portion of the visual system. This complex cognitive system explains why high-contrast visual acuity may not be a good predictor of visual function. This is especially important when evaluating highly aberrated eyes, such as in keratoconic patients. Their neural visual system compensates for long-term retinal image blur resulting in improved visual performance when compared with normal eyes exposed to the same optical aberrations ${ }^{(25)}$

\section{CONCLUSION}

This study showed that the NEI-RQL instrument used in conjunction with quantitative metrics was crucial for a comprehensive assessment of the influence of optical tests on patients' v-QoL. It allowed a better understanding of patients' outcomes with ICRS implantation and identified parameters that were significantly related to visual perception. ICRS implantation improves v-QoL due to low contrast improvement at 3 and $6 \mathrm{cpd}$ and reduction of the 
Table 1. Analysis of the influence of variables on QoL general scale of keratoconus patients measured by NEI-RQL (National Eye Institute Refractive Error Quality of Life) instrument

\begin{tabular}{|c|c|c|c|c|c|c|}
\hline \multirow[b]{2}{*}{ Variable } & \multicolumn{3}{|c|}{ Univariate GEE model } & \multicolumn{3}{|c|}{ Multivariate GEE model } \\
\hline & $\beta$ & SE & $p$ value & $\beta$ & SE & $p$ value \\
\hline Gender (female) & -6.56 & 3.19 & $0.0396^{\mathrm{a}}$ & -8.83 & 3.28 & $0.0071^{\mathrm{a}}$ \\
\hline Educational level & 4.65 & 3.67 & 0.2049 & & & \\
\hline Pupil diameter (millimeters) & -2.91 & 3.23 & 0.3674 & & & \\
\hline BCVA both eyes (logMAR) & -9.83 & 11.22 & 0.3809 & & & \\
\hline Cylinder & 6.68 & 1.17 & $<0.0010^{\mathrm{a}}$ & 5.06 & 1.50 & $0.0007^{\mathrm{a}}$ \\
\hline RMS LO & -5.36 & 1.47 & $0.0003^{\mathrm{a}}$ & -0.04 & 2.45 & 0.9874 \\
\hline RMS HO & -3.61 & 2.62 & 0.1670 & & & \\
\hline \multicolumn{7}{|l|}{ Contrast Sensitivity (CS) } \\
\hline Abnormality in A (1.5 cpd) & -12.25 & 3.57 & $0.0006^{\mathrm{a}}$ & -1.86 & 5.00 & 0.7096 \\
\hline Abnormality in B (3 cpd) & -15.63 & 3.91 & $<0.0001^{\mathrm{a}}$ & -8.43 & 4.16 & $0.0427^{\mathrm{a}}$ \\
\hline
\end{tabular}

$\beta=$ effect on general scale mean; intercept coefficients of univariate models were omitted; $\mathrm{SE}=$ standard error; $\mathrm{p}$-values for hypothesis $\mathrm{H}$ : $\beta=0$ (null effect); $\mathrm{BCVA}=$ best corrected visual acuity; $\mathrm{RMS} L \mathrm{LO}=$ root mean square low order; $\mathrm{RMS} \mathrm{HO}=$ root mean square high order; $\mathrm{cpd}=$ cycles per degree

${ }^{a}=$ values that had an influence on $\mathrm{QoL}$

cylinder component of the refraction. Developments in surgical technique and evaluation of the current outcomes in keratoconus patients must take into account such variables.

\section{ACKNOWLEDGEMENTS}

To Dr Wallace Chamon and Dr Luiz Alberto Vieira de Carvalho for having sent articles and discussed topics related to research, to Angela Paes for statistical analysis and for all physicians that sent us their patients to be included in this research.

\section{REFERENCES}

1. Rabinowitz YS. Keratoconus. Surv Ophthalmol. 1998:42(4):297-319.

2. Zadnik K, Barr JT, Edrington TB, Nichols JJ, Wilson BS, Siegmund K, et al. Corneal scarring and vision in keratoconus: a baseline report from the Collaborative Longitudinal Evaluation of Keratoconus (CLEK) Study. Cornea. 2000;19(6):804-12.

3. Marsack JD, Pesudovs K, Sarver EJ, Applegate RA. Impact of Zernike-fit error on simulated high- and low-contrast acuity in keratoconus: implications for using Zernike-based corrections. J Opt Soc Am A Opt Image Sci Vis. 2006;23(4):769-76.

4. Han DC, Mehta JS, Por YM, Htoon HM, Tan DT. Comparison of outcomes of lamellar keratoplasty and penetrating keratoplasty in keratoconus. Am J Ophthalmol. 2009;148(5): 744-51 e1. Comment in: Am J Ophthalmol. 2009;148(5):629-31.

5. Bahar I, Kaiserman I, Srinivasan S, Ya-Ping J, Slomovic AR, Rootman DS. Comparison of three different techniques of corneal transplantation for keratoconus. Am J Ophthalmol. 2008;146(6):905-912.e1.

6. Mendes F, Schaumberg DA, Navon S, Steinert R, Sugar J, Holland EJ, et al. Assessment of visual function after corneal transplantation: the quality of life and psychometric assessment after corneal transplantation (Q-PACT) study. Am J Ophthalmol. 2003;135(6):785-93.

7. Colin J, Simonpoli-Velou S. The management of keratoconus with intrastromal corneal rings. Int Ophthalmol Clin. 2003;43(3):65-80.

8. Colin J, Velou S. Current surgical options for keratoconus. J Cataract Refract Surg. 2003; 29(2):379-86.

9. Miranda D, Sartori M, Francesconi C, Allemann N, Ferrara P, Campos M. Ferrara intrastromal corneal ring segments for severe keratoconus. J Refract Surg. 2003;19(6):645-53.

10. Zare MA, Hashemi H, Salari MR. Intracorneal ring segment implantation for the management of keratoconus: safety and efficacy. J Cataract Refract Surg. 2007;33(11):1886-91.
11. Piñero DP, Alio JL. Intracorneal ring segments in ecstatic corneal disease - a review. Clin Experiment Ophthalmol. 2010;38(2):154-67.

12. Rabinowitz YS, Li X, Ignacio TS, Maguen E. INTACS inserts using the femtosecond laser compared to the mechanical spreader in the treatment of keratoconus. J Refract Surg. 2006;22(8):764-71. Comment in: J Refract Surg. 2007;23(3):221-2; author reply 222.

13. Kymes SM, Walline JJ, Zadnik K, Gordon MO; Collaborative Longitudinal Evaluation of Keratoconus study Group. Quality of life in keratoconus. Am J Ophthalmol. 2004;138(4): 527-35. Comment in: Am J Ophthalmol. 2004;138(4):637-8.

14. Sabesan R, Yoon G. Visual performance after correcting higher order aberrations in keratoconic eyes. J Vis. 2009:9(5):6.1-6.10.

15. de Freitas Santos Paranhos J, Avila MP, Paranhos A Jr, Schor P. Evaluation of the impact of intracorneal ring segments implantation on the quality of life of patients with keratoconus using the NEI-RQL (National Eye Institute Refractive Error Quality of life) instrument. Br J Ophthalmol. 2010;94(1):101-5.

16. Fink BA, Wagner H, Steger-May K, Rosenstiel C, Roediger T, McMahon T, et al. Differences in keratoconus as a function of gender. Am J Ophthalmol. 2005;140(3):459-68.

17. Ginsburg AP. Contrast sensitivity and functional vision. Int Ophthalmol Clin. 2003;43(2): 5-15.

18. Carney LG, Lembach RG. Management of keratoconus: comparative visual assessments. CLAO J. 1991;17(1):52-8

19. Negishi K, Kumanomido T, Utsumi Y, Tsubota K. Effect of higher-order aberrations on visual function in keratoconic eyes with a rigid gas permeable contact lens. Am J Ophthalmol. 2007;144(6):924-9.

20. Marsack JD, Parker KE, Pesudovs K, Donnelly WJ 3rd, Applegate RA. Uncorrected wavefront error and visual performance during RGP wear in keratoconus. Optom Vis Sci. 2007:84(6):463-70.

21. Applegate RA, Marsack JD, Ramos R, Sarver EJ. Interaction between aberrations to improve or reduce visual performance. J Cataract Refract Surg. 2003;29(8):1487-95.

22. Applegate RA, Sarver EJ, Khemsara V. Are all aberrations equal? J Refract Surg. 2002; 18(5):S556-62.

23. Boisjoly H, Gresset J, Charest M, Fontaine N, Brunette I, LeFrancois M, et al. The VF-14 index of visual function in recipients of a corneal graft: a 2-year follow-up study. Am J Ophthalmol. 2002;134(2):166-71.

24. Nunes LM, Schor P. [Evaluation of the impact of refractive surgery on quality of life using the NEI-RQL (National Eye Institute Refractive Error Quality of Life) instrument]. Arq Bras Oftalmol. 2005;68(6):789-96. Portuguese.

25. Sabesan R, Yoon G. Neural compensation for long-term asymmetric optical blur to improve visual performance in keratoconic eyes. Invest Ophthalmol Vis Sci. 2010;51(7): 3835-9. 